\title{
VIEW VIEWED AND VIEWER VIEWS: A "BOOK REVIEW" OF TRINH T. MINH-HA'S FRAMER FRAMED
}

Bernardo Alexander Attias

Book: n. 1a: a set of written sheets of skin or paper or tablets of wood or ivory b: a set of written, printed, or blank sheets bound together into a volume c: a long written or printed literary composition d: a major division of a treatise or a literary work e: a record of a business's financial transactions or financial condition - often used in $\mathrm{pl}<$ their - s show a profit> 2: cap : BIBLE.

Review: $\boldsymbol{n}$. 1: REVISION 1a: [an act of revising] 2a: a formal military inspection $\mathbf{b}$ : a military ceremony honoring a person or event 3: a general survey (as of the events of the period) 4 : an act or process of reviewing 5: judicial reexamination (as of the proceedings of a lower tribunal by a higher.

-Webster's Ninth New Collegiate Dictionary

Lurking within the meanings of words are surprises, excesses of connotation that perhaps reveal a politics. To produce a "book review" is already to engage oneself in the machinations of capital, religion, warfare, and the law. Before the project even begins the writer has already inserted h/erself into a violent economy of domination and subordination. To produce a "book review" of Trinh T. Minh-ha's most recently published text, Framer Framed, ${ }^{1}$ is to enter into that economy in a particularly inappropriate manner, for it is precisely the "book" and the "review" that much of Trinh's work throws radically into crisis. In order to do this text a modicum of justice, it is essential to begin with an admission of failure: this book 
review will be, indeed must be, inadequate to fulfill its project. In order to produce a book review of this text I must above all not produce a book review of this text.

And yet. Such a project is essential, if only for the trajectories which its failure will open up along the way. The other headings to which it will point even as it remains inadequate to its proper heading.

Trinh, in both her written work and her films, has always paid close attention to issues of style and form. In this work in particular, to analyze the substantive content without noting the format of the text is to miss the way in which Trinh's work performs. Trinh's work functions at several different levels, only one of which is argumentative. In addition to the persuasive nature of the text is its poetic nature: the text disrupts its expected behavior.

Like Woman Native Other and When the Moon Waxes Red, this work is littered with stills from Trinh's films. Also included are photographs of Trinh working and handwritten stage directions and pieces of script. Through these photographic images, Trinh interrupts the reading process quite directly; the reader must either pause in midsentence to examine the stills or turn extra pages to get back to the written word.

The work is divided into two parts: film scripts and interviews. While most of the interviews can be read as straightforward attempts to elaborate on and explain the theoretical substance of her films, the layout of these elements suggests that the very economy of the interview, traditionally understood as a diagnostic forum for an intellectual to explain her work more directly, is being radically disrupted here. By placing the film scripts first, the reader searching for clarity needs to skip 110 pages of fragments of poetry, photographs, and quotations before even getting to the interviews. Reading these printed scripts is an interesting exercise: in one sense, the reader reviews the films through the scripts. And yet the scripts function much differently from the films they script. With the printed text the reader has the opportunity to pause, to re-read and re-think a particular passage or image. In film, of course, such contemplation can only work through memory. "Film Scripts" suggests an illusion of control over the text - "if only I read and re-read these scripts I will produce knowledge of these films; through such knowledge I will be able to exercise control." This illusion is furthered by the section of interviews - "at last! The artist will be forced to answer questions about her work, to clearly and precisely tell us what her films are about!" Yet this illusion is disrupted precisely in the way this text is put together.

The last section of the text, "Which Way to Political Cinema?' A Conversation Piece," is an interview conducted by Trinh Minh-ha of two other filmmakers, suggesting a change in heading (the 
rest of the interviews being of Trinh by other scholars). The politics of the interview - the relationships between the interviewer (journalist) and the interviewee (public figure)-are displaced so that the "framer" escapes the frame. We expect Trinh to be the star (self) of the book; yet she effaces her self precisely at the moment of conclusion, of consummation (the end).

This last piece is further complicated by the fact that it stages a "conversation" which never took place by juxtaposing two separate conversations on alternate pages. It is impossible to read this piece without interruption. In this way, Trinh forces the reader to rewrite (review) the text with each reading. This text resists reading through its style so effectively that I am reluctant to call it a "book" and find it impossible to "review" it. The linear, progressive logic of traditional academic discourse and even the somewhat more playful (though primarily agonistic) logic of the traditional interview are displaced by the nomadic meandering of an embodied discourse which does at least as well as it tells. For the scholar thoroughly acquainted with the master's discourse, this text is a challenge. Its non-sense shortcircuits the rational faculties and forces a mutation of the very frame through which the reader approaches it: to make any sense of this text the reader is forced to reevaluate the very protocols of reading $s / h e$ brings to the text.

And yet. Meandering fragments of writing still function dialectically and rhetorically as writing. While the style of this work alone is radically disruptive and successfully performative, its substance more than adequately supplements this performance. Yet the substance of her arguments, she is careful to point out, is secondary to the movement of the forms through which she works:

\footnotetext{
Because of certain audience's reactions and because of the nature of the questions asked, I feel compelled (and have trained myself accordingly) to speak lucidly about my work. This is a defense mechanism that may have little to do with the work itself. The truth of reason is not necessarily a lived truth. So that if it is a question of intentions, then every event in the film can be given an intention. But any prior motivation for my film-what you call the need to be consciously political and polemical-simply did not enter into the working process. (239)
}

And yet these explanations, these political and polemical rationalizations, must nonetheless be taken seriously. While I have neither the space nor the inclination to detail each of the arguments made during these interviews, I will pick up a couple of threads that are woven into these conversations and attempt to "understand" them. Not to "know" them, clarify them, or control them, but to stand under them, to defer 
to them. Not to introduce 2 these threads to readers of this "review," but to approach them gently.

One question taken up in some of the interviews is a question of cultural and sexual identity. Trinh observes that these questions cannot be separated in her experience (240), and that the very notion of "identity" needs to be complicated. In particular, a site of resistance to cultural and sexual oppression cannot be forged through the assertion of identity alone. The self is already multiple and shifting. ${ }^{3}$ "A straight counterdiscourse," she points out, "is no longer threatening. It ultimately contributes to things remaining in place, because it tends more often than not to block critical thinking; it is unable to do much but repeat itself through the same anti-repressive rhetoric of modern ideology" (138). It is not enough to assert difference positively in order to challenge gender and racial hierarchy. She continues in another interview:

I make a distinction between an alienating notion of otherness (the Other of man, the Other of the West) and an empowering notion of difference. As long as Difference is not given to us, the coast is clear. We should be the ones to define this difference, even if, as I said in Naked Spaces, "all definitions are devices." And this, for me, is one way of summarizing how feminism could be understood and practiced. One cannot rely on essences (the essence of being a woman and/or non-white) and do away with the dialectic and problematics of things. In a way, a feminist always has at least two gestures at the same time: that of pointing insistently to difference, and that of unsettling every definition of woman arrived at. ...While rendering Difference visible and audible in my films (as well as in my books and poems), I also have to move on, repeating what is shown or said earlier in different contexts, so as to remind the viewer that the not-quitenot-yet-it is always present. . . Being truthful to oneself and to one's making is, as said in another statement of the film, "being in the in-between of all definitions of truth." (186)

Identity, then, ethnic and female identities, are moved along a trajectory of becoming rather than a trajectory of being. To be truthful is to understand becoming as a process, to read a noun ("woman of color," for example, or, perhaps, "review") as a verb.

Another thread woven into this one deals with the politics of translation. In a sense, this text is set up as a translation: the scripts of the films and the transcripts of the interviews can be read as "translations" of Trinh's films. Translation, Trinh suggests,

implies the question of language, power and meaning; or more precisely in this film, of women's resistance vis-à-vis the sociosymbolic contract-as mothers, wives, prostitutes, nurses, doc- 
tors, state employees, official cadres, heroines of the revolution. In the politics of constructing identity and meaning, language as translation is necessarily a process whereby the self loses its fixed boundaries - a disturbing yet potentially empowering practice of difference. For me, it is precisely in fighting on more than one front at a time-that is, in fighting not only against forms of domination and exploitation but also against less easily locatable forms of subjection or of binarist subjectivity - that the feminist struggle and other protest movements can continue, as discussed earlier, to resist falling back into the consolidation of conformism. (133)

To translate is always to (re)write. To write is already to control, to manage, to establish categories of meaning and to consolidate an identity. But not to translate, not to write, is impossible, or at least irresponsible. The potential excess of translation, the difference within repetition (for repetition is always repetition with a difference), can be mobilized against the very power which operates (through) writing.

Throughout this work, both stylistically and substantively, Trinh disrupts a traditional meaning-oriented approach to language. Yet this disruption is meaningful, becomes meaningful through the operations it performs on meaning. This book is utter nonsense-if nonsense is understood as non-sense, that which interrupts the sense-making process and forces a mutation of the categories and grids of intelligibility through which sense is produced. The goal is not to refute the master discourse but to produce another kind of discourse alongside of it which radically disrupts its processes of domination and intimidation. Do not read this book, for it cannot be read. Experience it, stand under it, and it will produce anxieties, dislocations, and interruptions.

\section{Notes}

1 Trinh T. Minh-ha, Framer Framed (New York: Routledge, 1992).

2 "Intro-duce." "Intro-": in, into, inside, to the inside. "Duce": to lead, direct, control (Il Duce). "Introduce": to lead into, to direct to the inside, "point the way," as it were, but above all to enter by force, to insert (as in "the introduction of foreign material into the blood"), to inhabit, to settle, to colonize. The police and the military are never far away, waiting to check identity papers and credentials.

${ }^{3}$ This effacement and decentering of the self is a theme which operates throughout Trinh's work. In Woman Native Other: Writing Postcoloniality and Feminism (Bloomington: University of Indiana, 1989), Trinh decenters the subject-who-writes through the first-person pronoun I/i: I, the all-knowing subject, the raceless genderless Author preceding the text who is always white and male, and $i$, the "personal 
race- and gender-specific subject" (9), are sublated to produce $I / i$, a subject which preserves something of both $I$ and $i$ and yet exceeds each container. While the $I$ is constructed by the master's word, the $i$ is constructed by the subject's situated experiences. I/i is a multiplicity that always exceeds the boundaries of I-“categories leak" (94).

Clarity in writing functions to dissolve the historical specificity of $i$ into the universality of $\mathrm{I}$-clarity presumes transparency of discourse, objective "description" that has no proscriptive function. Clarity makes writing a tool, a means to an end (revealing) rather than an act in itself (16). The writer must turn on herself in writing so as not to lose i in I: she must recognize that she is written even as she writes: "Yet Ithe-writer do not express (a) reality more than (a) reality impresses itself on me. Expresses me. . She writes... to possess and dispossess herself of the power of writing" (18). 